\title{
Esstados Unidos y el proceso de transnacionalización \\ en la postguerra
}

\section{INTRODUCGIÓN}

Durante los 25 años que siguieron a la terminación de la Segunda Guerra Mundial, los países capitalistas avanzados atravesaron por un período de expansión económica sin precedentes que culminó, a comienzos de los setenta, en una prolongada crisis económica de la que aún no se recuperan. A lo largo de este período de crecimiento sostenido se registró, en una dimensión y extensión sin precedentes, un proceso de transnacionalización y creciente vinculación intercapitalista.

Una recapitulación de los elementos centrales de la fase expansiva de postguerra pone de manifiesto el papel clave jugado por el incremento de las vinculaciones económicas entre los países capitalistas avanzados, primero a través de mecanismos comerciales, luego productivos y más tarde financieros. En este proceso adquiere especial relevancia el rol desempeñado por Estados Unidos como polo hegemónico. En efecto, fue en torno a su poderío económico, político y militar que se organizó institucionalmente el capitalismo de postguerra. Asimismo, fue sobre la base del dinamismo del capital norteamericano que se movilizó la energía del resto de las economías avanzadas, dando origen a un proceso de reacción oligopólica de formidable dimensión.

La creciente vinculación intercapitalista y el papel crucial jugado en este proceso por las empresas multinacionales llevó a muchos analistas a sostener que se estaba gestando una integración tan efectiva de la economía mundial que ésta acabaría por ordenarse sobre la base de una Iógica global de acumulación en la cual los Estados nacionales aparecerían, cada vez con mayor nitidez, como resabios de un orden anterior. Esta posición era sostenida no sólo por apologistas de la empresa transnacional, sino también por analistas menos ortodoxos que, no obstante, compartían la hipótesis de viabilidad de alguna forma de "superimperialismo" (la economía y las empresas transnacionales norteamericanas se transformarían en absolutamente hegemónicas) o de "ultraimperialismo" (una coalición

$$
\text { [ } 9 \begin{array}{lll}
9 & 4 & \text { ] }
\end{array}
$$


de Estados imperialistas relativamente autónomos garantizarian el nuevo orden mundial).

La realidad se ha mostrado hasta ahora bastante más conflictiva. Aun cuando la evolución del fenómeno transnacional sirvió para poner en cuestión la efectividad de ciertos instrumentos de política económica característicos del Estado nacional posterior a la Gran Depresión y para relativizar la importancia del espacio original de acumulación para las grandes empresas transnacionales, la competencia entre capitales y Estados nacionales y entre cada Estado nacional y el capital "transnacionalizado" se ha agudizado. Sin duda alguna, el período de crisis por el que atraviesa la economía capitalista ha tenido una gran dosis de responsabilidad en la acentuación de estas contradicciones.

La visión "optimista" a que nos referíamos dejaba de lado en su análisis el papel crucial jugadó por el Estado nacional en la constitución del orden transnacional de postguerra. Además de las dinámicas propias de la acumulación de capital en los países centrales que presionaban hacia la internacionalización de los segmentos más dinámicos de su estructura productiva, fue un Estado nacional dominante el que sentó las bases institucionales y políticas para la expansión acelerada de los vínculos intercapitalistas. La crisis económica que se registra desde principios de los setenta refleja, en parte, la desintegración de ese orden edificado sobre la base de la hegemonía norteamericana, las contradicciones crecientes entre distintos Estados y capitales nacionales, y la agudización de ciertas manifestaciones contradictorias de la relación entre cada Estado nacional y el capital "transnacionalizado". En períodos de reestructuración como el que actualmente atraviesan las economías capitalistas, ninguno de estos procesos es necesariamente definitivo. No obstante, apuntan a algunas de las contradicciones que se han agudizado como consecuencia de la acelerada expansión del fenómeno transnacional.

La expansión transnacional en Estados Unidos durante la década de los cincuenta y de los sesenta parecía complementaria de la doméstica, o al menos no presentaba signos de evidente conflicto abierto. Aún en el resto de los países capitalistas avanzados, los interrogantes y las advertencias levantadas por el clásico "El desafío americano" pronto quedarían a un lado ante la evidencia de que las propias economías europeas y la de Japón estaban articulando una respuesta oligopólica eficiente al reto que representaba la expansión acelerada del capital norteamericano. La crisis económica en los setenta y el consiguiente incremento en la rivalidad intercapitalista sirvieron para poner en debate la cuestión relativa a la complementariedad de la relación entre transnacionalización y crecimiento interno en las economías capitalistas avanzadas. Aún en la propia economía capitalista más desarrollada - Estados Unidosel debate en torno a los efectos de la transnacionalización sobre el 
aparato productivo local y la capacidad del Estado para afectar las condiciones económicas se hizo particularmente intenso.

Este hecho refleja la dificultad que el capital transnacionalizado encuentra, en las actuales circunstancias, para legitimar su papel decisiyo en el proceso de acumulación a escala global y a nivel nacional. La emergencia de un conflicto explícito entre las necesidades de las economías domésticas y la lógica internacional de estas fracciones de capital pone de manifiesto las contradicciones que en el pasado se habían mantenido latentes, ocultas por el rápido crecimiento económico de postguerra.

Es por esto que las visiones "optimistas" de un futuro armonioso administrado por un puñado de políticos y ejecutivos "globales" están en tela de juicio. No obstante, tampoco parece plausible una visión apocalíptica que anticipe un retorno al "nacionalismo" a ultranza característico de la década de los treinta: las economías capitalistas se encuentran en la actualidad mucho más entrelazadas que hace medio siglo. La actual ofensiva neoliberal en algunos de los principales países capitalistas avanzados, en particular en Gran Bretaña y Estados Unidos, intenta restablecer la disciplina de mercado como lógica de reordenamiento global. No obstante, contiene una profunda esquizofrenia que se refleja en el abismo que existe entre la práctica y la retórica de las relaciones económicas internacionales y entre el liberalismo global y el proteccionismo aplicado a casos específicos. Las tensiones generadas por esta estrategia son, sin embargo, evidentes. Tanto a nivel interno como internacional, el último par de años ha revelado que el restablecimiento de la disciplina mercantil como lógica de ordenamiento agudiza los conflictos a la vez que reproduce, amplificadamente, el caos de la competencia oligopólica.

En tanto la crisis se supera y en el proceso se dibuja un orden futuro, el curso más probable para los próximos años parece ser el de una continuación de la ya bien asentada tendencia a la politización de las relaciones económicas. Los costos de la imposición de una lógica estrictamente mercatil probablemente se harán demasiado elevados como para que los sucesos de los dos últimos años constituyan algo más que una etapa coyuntural en una sucesión de intentos, hasta ahora fracasados, para reordenar las economías capitalistas avanzadas.

En estas notas se incluyen tres temáticas. En primer lugar, se reseña brevemente la evolución del proceso de transnacionalización en la postguerra, concentrando el análisis en la dinámica de la economfa de Estados Unidos. En un segundo apartado se discuten algunos de los elementos propios de la transnacionalización que, en la coyuntura actual, representan fuentes de conflicto ya sea para la economía norteamericana o para la administración del orden internacional. En tercer lugar se hace una apretada reflexión alrededor 
Roberto Bouzas / Estados Unidos y el proceso de transnacionalización ...

de los tres intentos más articulados de respuesta al desorden de los setenta.

\section{TENDENCLAS DEL PROGESO DE TRANSNAGIONALIZACIÓN EN LA POSTGUERRA}

En el periodo de postguerra pueden identificarse tres grandes fases en el proceso de transnacionalización cuando éste es observado desde la perspectiva de los acontecimientos en los países capitalistas avanzados, y particularmente de Estados Unidos. Estas son:

a) la fase de hegemonía absoluta norteamericana, que comprende el período que va de la inmediata postguerra hasta mediados de la década de los cincuenta;

b) el período del Ilamado "desafío americano", que se extiende desde mediados de los cincuenta hasta mediados de la década de los sesenta; y

c) el períado de desarrollo y profundización de la crisis.

a) La fase de hegerronia absoluta norteamericana: el perfodo inmediatamente posterior a la Segunda Guerra Mundial fue testigo de un gigantesco esfuerzo de asentamiento de las bases para una efectiva integración de la economía internacional. La profunda huella dejada por la década de los treinta hacía explícitos los riesgos encerrados en la posibilidad de un retorno a las experiencias de "racionalismo económico" y a las llamadas políticas de "transferencia de la carga al vecino". Es así como en lơs años que siguen a la terminación de la Segunda Guerra Mundial se implementa un ambicioso proyecto de desmantelamiento de las barreras al comercio y, más en general, a la interacción económica. Esto ocurre por la vía de la destrucción de los bloques comerciales y monetarios, particularmente a expensas de Gran Bretaña. La implementación de este proyecto se hizo posible gracias a la existencia de una potencia económica, política y militar que gozaba de hegemonía absoluta sobre sus competidores. Gran Bretaña, otrora pass rector del capitalismo mundial, fue incapaz siquiera de imponer condiciones relevantes en el diseño del nuevo orden internacional, teniendo que subordinarse a los dictados de la potencia que objetivamente recogeria los mayores beneficios de tal proceso. Los países derrotados en el conflicto bélico aceptaron sin mayor cuestionamiento el contenido de la nueva institucionalidad, a la vez que se beneficiaron del grueso de la ayuda y de la transferencia de recursos a contar de 1948.

Es bien sabido que el debate que tuvo lugar en la inmediata postguerra en Estados Unidos en relación al contenido de su política exterior mostró grandes dificultades para consolidar el predominio de la estrategia "internacionalista" vis-a-tis aquellos que sostenían una postura de retorno al aislamiento. Aun cuando la preocupación del gobierno norteamericano por "abrir" el orden inter- 
nacional estaba presente en los esfuerzos diplomáticos que se desarrollaron desde comienzos de la guerra (los condicionamientos impuestos a Gran Bretaña en ocasión de la firma de los acuerdos lendlease a principios de los cuarenta, son una prueba de ello), el predominio de esta estrategia durante la postguerra estaba lejos de estar asegurada. La omnipresencia del problema de la reconversión y de la necesidad de mantener niveles de empleo relativamente elevados en una "economía de paz" fue cómplementada decisivamente con el argumento de la "amenaza comunista" a contar de 19471948, permitiendo así generar un consenso favorable - particularmente entre un Congreso reacio- a la reconstrucción y a la transferencia de recursos a Europa y Japón.

Una Europa y un Japón destruidos y empobrecidos difícilmente podrían sostener un impulso de demanda externa significativo por un periodo prolongado de tiempo, a la par que registrarian condiciones de elevada inestabilidad política. La transferencia de poder de compra a través del Plan Marshall primero y del rearme más tarde, cumplirian este papel en la última parte de los cuarenta y a principios de los cincueñta. La reconstrucción de las economías europeas y de Japón lo garantizarían en el largo plazo, sentando contradictoriamente las bases de su propia destrucción ${ }^{1}$

Este período registró un notable incremento en los intercambios comerciales en comparación con la experiencia de la década de los treinta, acompañado de un significativo aumento en los flujos de capital. Entre 1946 y 1955 la inversión privada norteamericana creció en valores corrientes en $116 \%$, mientras que la inversión directa lo hizo en $170 \%$. En valores constantes, esta última creció a tasas promedio de casi $8 \%$ anual. La distribución regional de esta nueva inversión directa se concentró mayoritariamente en Canadá y en América Latina, regiones tradicionalmente receptoras de inversión norteamericana. Ambas regiones absorbieron un $64 \%$ del incremento total en la inversión norteamericana en el extranjero, mientras que a Europa Occidental apenas Ie correspondió un 13\%. El destino sectorial de la inversión se concentró en minería y petróleo, hacia donde se dirigió aproximadamente el $50 \%$ del total de la inversión norteamericana directa. El sector manufacturero absorbió apenas el $38 \%$ del incremento total, concentrado en un $70 \%$ en América Latina y Canadá.

Estos datos sobre la inversión norteamericana en el exterior re-

${ }^{1}$ En tanto que entre 1931 y 1940 el superávit comercial externo norteamericano alcanzó un promedio de 500 millonés de dólares (aproximadamente un $0,65 \%$ del producto nacional bruto), entre 1946 y 1955 se multiplicó por diez, alcanzando un promedio de 5.000 millones de doblares $(1,43 \%$ del producto nacional bruto).

En este perfodo es particularmente notable el incremento en el saldo favorable del comercio de bienes de capital y, después de $195 \mathrm{i}$, de productos militares. 
Roberto Bouzas / Estados Unidos y el proceso de transṇacionalización...

flejan que el grueso de la filiarización se produjo en regiones tradicionalmente receptoras de flujos de capital descle Estados Unidos ${ }^{2}$ y en sectores también tradicionales, concretamente la minería y el petróleo. Aun cuando la inversión en la manufactura registra un aumento importante, no será sino hasta el período siguiente en que superará a la que se dirigía a sectores tradicionalmente receptores.

Durante este período, el flujo de inversión extranjera hacia Estados Unidos es poco significativo. Además de que los valores absolutos son muy dispares ${ }^{3}$, entre 1946 y 1955 la inversión directa norteamericana en el exterior creció en una proporción de $170 \%$, mientras que la inversión extranjera directa en. Estados Unidos lo hizo en apenas 100\%. Esta disparidad refleja las diferentes dinámicas del proceso de transnacionalización en Europa y' en Estados Unidos en la década que sigue a la terminación de la Segunda Guerra Mundial.

b) El periodo del "desafio americano": el período que va desde mediados de la década de los cincuenta hasta la segunda mitad de los sesenta constituye una fase de rápida transnacionalización, en la cual se produce una sustancial filiarización en el sector manufacturero, comienza a sentarse las bases para el desarrollo de un mercado financiero internacional privado y se produce una dinámica reacción oligopólica por parte de los capitales europeos y japoneses a la rápida expansión de las empresas transnacionales norteamericanas.

AI igual que en el perfodo anterior, el patrón de crecimiento de las economías capitalistas avanzadas descansa en la dinámica de las ramas metalmecánica, química y petroquímica del sector industrial. Estos sectores más dinámicos en términos de crecimiento son, asimismo, los que registran mayores niveles de transnacionalización, lo cual provoca una significativa uniformación del patrón industrial y tecnológico al interior de las economías capitalistas avanzadas, sobre el modelo de su exponente más avanzado: Estados Unidos.

Entre 1955 y 1967 la inversión directa norteamericana en el extranjero creció en poco más del $200 \%$, mientras que la inversión extranjera directa en Estados Unidos aumentó en algo menos de $100 \%$. A pesar de este crecimiento diferencial existe evidencia más especifica, que muestra que el subsistema de empresas transnacionales europeo y japonés creció con mayor rapidez que el norteamericano, probablemente como consecuencia de su implantación original en áreas de crecimiento económico más elevado.

${ }^{2} \mathrm{En}$ verdad, América Latina venía mostrando una tendencia decreciente en su absorcion desde la década de los veinte.

${ }^{3} \mathrm{E}$. 1955 la inversión norteamericana directa en el extranjero alcanza un monto total de 19.400 millones de dólares, mientras que la inversión, extranjera directa en Estados Unidos apenas llega a los 5.000 millones. 
En lo que respecta a la inversión de Estados Uniclos en el exterior, y a diferencia del período anterior, el grueso de su incremento se concentró en la manufactura (44\% del total en comparación con un $35 \%$ en minería y petróleo) y en Europa Occidental (un $37 \%$ del total en comparación con un $39 \%$ en Canadá y América Latina). Estudios más específicos demuestran que el grueso de las salidas netas de capital de Estados Unidos se dirigió esencialmente a países capitalistas avanzados, financiándose la mayor parte de la nueva inversión en los países subdesarrollados con reinversión de utilidades.

Durante este período se produce el tránsito de lo que se ha dado en llamar el período de "escasez de dólares" al de "abundancia de dólares". En efecto, a contar de 1958 la economía norteamericana comienza a mostrar una tendencia sistemática a los déficit crónicos en su balanza de pagos, registrándose una continua reducción en sus reservas y una salida neta de dólares, situación que finalmente desembocará en la crisis monetaria de agosto de 1971.

Las diferencias en los ritmos relativos de crecimiento de las distintas economías capitalistas avanzadas a que nos referimos líneas más arriba se reflejó, entre otras cosas, en crecimientos diferenciales en los niveles de productividad y en cambios significativos en la participación de las distintas economías en el comercio mundial de manufacturas ${ }^{4}$. Esto reflejabi las dificultades de Estados Unidos para sostener la superioridad económica incontestada con que emergiera de la Segunda Guerra Mundial.

En este período, el grueso de la filiarización se produce en el contexto de una estrategia de largo plazo de crecimiento y ocupación de espacios de mercado por parte de las empresas transnacionales, más que como consecuencia de un intento por parte de éstas por obtener ventajas comparativas de costo a fin de competir en el mercado internacional. La inversión dirigida a las regiones subdesarrolladas intentaba -al menos en lo que respecta a América Latina-ganar posiciones en mercados cuyo acceso por la vía comercial estaba siendo obstaculizado por la aplicación de políticas sustitutivas de importaciones. Parece relativamente claro, entonces, que el auge de la inversión directa fue más bien el resultado de la búsqueda de posiciones en mercados en rápida expansión que un mecanismo para reducir costos de producción en una estrategia de competencia en el mercado internacional. Como se verá más ade-

"Entre 1955 y 1967 el producto interno bruto por persona empleada creció a una tasa anual de $2,1 \%$ en Estados Unidos, mientras que lo hacía en $7,8 \%$ en Japón, en $5 \%$ en Francia y en 4,2\% en Italia. Las diferencias registradas en las tasas de crecimiento del producto industrial por hora son aún más impresionantes, duplicando y triplicando los registros norteamericanos.

De igual modo, mientras que en 1956 Estados Unidos aportaba el $23 \%$ del total de las exportaciones manufactureras, para 1967 su participación habfa decaído al $16 \%$. 
lante, en la fase siguiente, esta última modalidad adquirirá una importancia mayor.

c) El desarrollo de la crisis: 1967 representa un hito en la historia reciente del capitalismo. En ese año se produce la primera crisis monetaria profunda desde el realineamiento de las monedas europeas en 1949. La devaluación de la libra esterlina anticipaba lo que pocos años después habría de ocurrir con el dólar norteamericano.

En la segunda mitad de los sesenta, Estados Unidos experimenta una significativa acumulación de presiones inflacionarias que, junto con otros factores y en un contexto de tipos de cambio fijos, provoca una caída en la competitividad de importantes segmentos de la industria manufacturera norteamericana. Durante la última parte de los sesenta los costos unitarios de la mano de obra crecieron en Estados Unidos a ritmos que eran casi el doble de los que se registraban en los principales paises competidores. Igualmente, los valores unitarios de las exportaciones norteamericanas crecieron a tasas sostenidamente más elevadas que las del resto de los países capitalistas avanzados.

A lo largo del mismo período también se registra en la economia de Estados Unidos un notable estancamiento en la evolución de la productividad, un deterioro en la rentabilidad del capital industrial, un endeudamiento personal y corporativo sostenido, y una reducción progresiva en el superávit comercial y en la balanza de manufacturas. En medio de presiones en aumento sobre el dólar, en 1971 se registra el primer déficit comercial del siglo para Estados Unidos. En agosto de ese mismo año el Presidente Nixon implementa un paquete de medidas de política económica que de hecho consisten en un repudio unilateral por parte de Estados Unidos a los acuerdos de Bretton Woods que se habían montado bajo su propia dirección. El círculo estaba cerrado.

Después del boom especulativo de los años 1972-1973, las economías capitalistas cayeron en una profunda crisis económica -la más severa desde la Gran Depresión-, a la que sigue un período de lento e inestable crecimiento del cual aún no se recuperan. Durante este lapso es notoria la desarticulación de la hegemonía norteamericana a nivel internacional, así como la creciente gravedad de los problemas domésticos que enfrenta la economía de Estados Unidos. Si bien este país continúa siendo la potencia económica más poderosa, pierde su capacidad de hegemonizar al conjunto del mundo capitalista desarrollado producto de sus propias dificultades tanto como de la diferenciación de intereses con sus principales competidores. Esto se refleja en la creciente politización de las relaciones económicas internacionales que tiene Iugar a lo largo de la década de los setenta, y en tránsito progresivo a un proceso más activo de negociación en materias internacionales. Las sucesivas reunio- 
nes "cumbre" de los siete grandes intentando armonizar las políticas macroeconómicas, energéticas, y otros aspectos de importancia vital para las economías capitalistas avanzadas, son una muestra de ello. La explicación del conflicto Norte-Sur después de la "crisis cie los energéticos" y el debate relativo a la creación de un Nuevo Orden Económico Internacional reflejan, desde otro ángulo, el mismo proceso.

Si bien los ritmos de crecimiento de la inversión norteamericana total en el exterior se mantienen dentro de los registros de las dos últimas décadas, se produce una significativa contracción en la tasa de crecimiento de la inversión directa en valores constantes. A esta disminución le corresponde un notable incremento de la inversión extranjera en Estados Unidos. Durante este período esta última registra tasas de crecimiento muy superiores a las de la inver. sión norteamericana en el exterior. Algunos analistas de este fenó. meno de rápida penetración del capital extranjero en Estados Unidos enfatizan las ventajas que ofrece la economía de Estados Unidos en térninos de mercado, estabilidad, etc. para la radicación de capitales. Sin embargo, estas cualidades no son una novedad de la década de los setenta. El elemento decisivo en el desencadenamiento de este fenómeno tiene que ver con la maduración de las economias y las empresas europeas y japonesas que alcanzan la capacidad de invertir, en condiciones de igualdad con las grandes firmas norteamericanas en el principal mercado del mundo capitalista.

La inversión directa continuó orientándose en su mayoría a los sectores y regiones característicos de la postguerra (la manufactura y los países capitalistas avanzados), aunque comienza a producirse un nuevo fenómeno que habrá de tener importancia creciente en el ámbito de las relaciones intercapitalistas. Nos referimos a la modalidad de inversión directa en la manufactura en países con bajos costos salariales con el objeto de aprovechar estas diferenciales y favorecer la posición competitiva en el mercado internacional. Este fenómeno agudizará las tensiones entre los Estados con economías estancadas y las fracciones de capital "transnacionalizado", por cuanto la instalación de plantas en el exterior será visualizada como responsable por el incremento en el desempleo, el deterioro regional y el desequilibrio externo.

En este mismo período resalta por su magnitud el significativo cambio en la composición de los flujos internacionales de capital, y el notable incremento en la inversión a corto plazo ligada a la consolidación de un mercado.

a) Transnacionalización y manejo de la demanda agregada: desde la "revolución keynesiana" el manejo de la demanda agregada como factor de estabilización de las fluctuaciones cíclicas ha estado presente en el diseño de la política macroeconómica. Durante el período de postguerra, y con diferentes modalidades nacionales, el 
Estado ha jugado un papel central en la regulación de la evolución económica de corto plazo. En algunos casos específicos, el Estado ha jugado un papel mucho más decisivo en la dirección del proceso de acumulación y en el estímulo a la constitución de bloques de capital oligopólicos capaces de enfrentar en condiciones de igualdad la aguda competencia internacional. La integración creciente de las economías capitalistas ha planteado, sin embargo, nuevos problemas y limitantes a la efectividad de la política económica convencional de manejo de la demanda agregada.

Sintéticamente, el notable incremento en la movilidad del capital que, para los patrones históricos, conlleva el fenómeno de la transnacionalización hace posible que estas fracciones de capital encuentren condiciones más favorables para evitar o reducir el impacto de la política económica convencional. Un ejemplo frecuentemente citado es el relatîvo a la inefectividad, o por lo menos al impacto diferencial, de la política monetaria tradicional sobre los segmentos más transnacionalizados de cada economía nacional. La restricción de la liquidez doméstica no afecta con la misma intensidad al sector oligopólico y transnacionalizado en la medida en que éste tiene patrones específicos de determinación de precios $y$, lo que es más importante para nuestro análisis; tiene la capacidad de generar su propio financiamiento por la vía de sus operaciones internacionales o bien de recurrir al mercado financiero internacional para obtenerlo. Lo que es más, los grandes volúmenes de liquidez manejados por el capital transnacional son capaces de poner en apuros la estabilidad de políticas monetarias o de tipo de cambio implementadas por un Estado nacional:

En diversas ocasiones se ha confundido la cuestión relativa a la efectividad o inefectividad de la política macroeconómica convencional con el argumento del debilitamiento del Estado nacional como instrumento de regulación económica. Ciertamente la transnacionalización ha afectado la influencia que tenía el Estado a través del uso de los instrumentos convencionales de política económica. Este fenómeno dice más sobre la propiedad de la política macroeconómica vigente que sobre la naturaleza del poder estatal.

Conviene apuntar, asimismo, que esta debilidad relativa es asimétrica para los distintos Estados nacionales en función de su posición en la jexarquía internacional de poder económico. Por cierto que Estados Unidos se vio forzado a tomar en consideración factores "externos" en la definición de su política económica (particularmente monetaria) en ciertos períodos de la década pasada. El ejemplo clásico tuvo lugar en octubre de 1978, cuando la Administración Carter se vio obligada a implementar un programa monetario orientado a detener la vertiginosa caída del dólar en los mercados monetarios internacionales. No obstante, este hecho no puede compararse con la dependencia que aún mantienen otras economías 
capitalistas avanzadas en lo que toca ạ la definición de su propia política económica doméstica.

La estrecha interrelación de los mercados financieros $y^{\prime}$ monetarios nacionales a través del espacio internacional hace que las influencias entre las políticas monetarias individuales (en especial la que se dirige del país con patrón monetario hegemónico a los restantes) se procesen con extrema rapidez. En efecto, en un contexto de apertura económica $y$ capitales altamente móviles, la política monetaria del país con moneda patrón es altamente decisiva para las restantes economías. Como ha quedado suficientemente demostrado con la experiencia reciente de la Administración Reagan, la existencia de tipos de cambio flotantes en un contexto de inflación $y$ mercados financieros estrechamente vinculados con el exterior, no modifica sensiblemente la discrecionalidad de cada Estado nacional en la definición del carácter de su política monetaria.

La política monetaria implementada por la Administración republicana en Estados Unidos ha tenido profundos y bien conocidos efectos sobre el resto de los países capitalistas avanzados, reflejando esta dependencia y alertando, al mismo tiempo, respecto de aquellas visiones extremas que asignan a Estados Unidos una incapacidad para afectar significativamente la situación económica de sus competidores. Al extender su influencia al conjunto de un mundo capitalista con mercados financieros y monetarios integrados, la política monetaria norteamericana vuelve a recuperar la capacidad de afectar las condiciones de la liquidez doméstica e internacional y, por lo tanto, de influir sobre su propio capital "transnacionalizado". Obviamente, esta influencia aparece atenuada a la vez que la profundidad de las medidas de política económica que exige son cada vez mayores.

En conclusión, es notorio el debilitamiento de los instrumentos convencionales de manejo de la demanda agregada en el plano nacional. No obstante, Estados Unidos conserva un cierto grado de influencia sobre el mercado internacional que reproduce una situación de profunda asimetría entre Estados nacionales que se agrega a la asimetría de la política económica convencional sobre distintas fracciones de capital. Este fenómeno no debe confundirse con la pérdida de poder del Estado-nación, sino con la necesidad de diseñar instrumentos de política económica más apropiados que no necesariamente representan una revolución mayor que la que representó la "revolución keynesiana" en los treintas en relación al consenso entonces dominante. Esta afirmación no resuelve, ciertamente, el problema relativo a la capacidad política de implementación de políticas económicas alternativas.

b) Transnacionalización, economia doméstica y legitimación del patrón de crecimiento: el patrón de crecimiento transnacionalizado que se consolidó en el período de postguerra fue funcional, duran- 
te la fase de crecimiento, al desarrollo económico de Estados Unidos. La apertura de la economía internacional a un aparato productivo pujante y la emergencia del dólar como patrón monetario hegemónico tuvieron obvias repercusiones favorables sobre la economía norteamericana. La cristalización a nivel ideológica de la estrecha complementariedad entre las necesidades de la economía doméstica y la expansión transnacional se resume en la convicción generalizada por un largo tiempo en Estados Unidos en el sentido de que la protección y el estímulo de las empresas norteamericanas era la protección y el estímulo de la economía de Estados Unidos. Sin embargo, paralelamente a la expresión de esta complementariedad se estaban gestando procesos que eventualmente manifestarían una nítida contradicción entre Ia expansión transnacionàl y las demandas del aparato productivo doméstico. En efecto, en la actualidad la expasión transnacional plantea serias dificultades a la recomposición clel aparato productivo local castigado por la crisis económica y al aseguramiento de condiciones de legitimidad polftica al patrón de crecimiento de la economía de Estados Unidos.

A lo largo de la década de los setenta se ha ido intensificando un debate que era prácticamente inexistente: el relativo a los efectos de la inversión norteamericana en el exterior sobre el aparato productivo local, la solidez industrial y los niveles de empleo en Estados Unidos. EI fortalecimiento de las economías europeas y de Japón y la emergencia de los llamados "NIc's" sentaron las bases para el incremento sostenido en las importaciones norteamericanas de manufacturas que, en un contexto de crisis económica, estancamiento productivo y elevada desocupación, provocó una aguda reacción por parte de ciertos sectores sociales que atribuian a la salida de capitales de Estados Unidos la responsabilidad por tal estado de cosas.

Esta posición contraria a la salida de capital al exterior es particularmente fuerte en segmentos importantes del movimiento obrero norteamericano, el que explica los mayores niveles de desempleo característicos de la década de los setenta, como un resultado de la mayor movilidad que ha adquirido la empresa transnacional durante el período de postguerra y de su capacidad de reubicarse internacionalmente con relativamente pocas dificultades. Este razonamiento se ha fortalecido ante la emergencia de un conjunto de pafses con bajos costos salariales que han atraido una buena cantidad de inversión extranjera directa movilizada en busca de ventajas relativas para competir efecientemente en un mercado mundial crecientemente integrado. En el razonamiento de los sindicatos norteamericanos, la inversión extranjera "exporta" puestos de trabajo que podrían haber sido creados al interior de Estados Unidos para luego "destruir". más empleos por la vía de exportar hacia Estados Unidos desde países con menores costos de mano de obra. 
Por cierto, la discusión relativa a los efectos de la inversión en el exterior sobre los niveles de ocupación en el largo plazo es sumamente dependiente de los supuestos que se incorporen en el razonamiento. De hecho, distintas investigaciones empíricas han arribado a resultados contradictorios como consecuencia, precisamente, de la sensibilidad de las conclusiones a la elección de los supuestos. Lo que aquí nos interesa destacar no es la responsabilidad efectiva que la inversión en el exterior puede tener sobre los niveles de desocupación en la década pasada, sino simplemente señalar cómo el cuadro de crisis y estancamiento económico ha puesto en cuestión la legitimidad del patrón de crecimiento transnacional.

En el corto plazo, y en un período de estancamiento o lento crecimiento económico, las contradicciones entre la inversión en el exterior y el equilibrio regional y los niveles de desempleo son ciertamente más evidentes. Es también evidente, tal como lo discutimos en el apartado anterior, que la creciente movilidad de las fracciones transnacionalizadas del capital ha planteado limitaciones a la capacidad de influencia de la política económica convencional. No obstante, conviene tener presente que los segmentos más transnacionalizados de cada economía nacional normalmente se corresponden con los sectores más dinámicos del aparato productivo. Esta paradoja encuentra parte de su explicación en las condiciones de crisis o de rápido crecimiento económico por las que atraviesa una economía particular.

c) Reestructuración industrial y transnacionalización: las exigencias de reestructuración de ciertas ramas industriales y las presiones para su reubicación èn ciertas áreas geográficas o para su contracción absoluta plantea una abierta contradicción entre la necesidad de "programar" dicha transición a efectos de reducir sus implicaciones sociales y la tendencia a un ajuste violento promovido por un capitál altamente móvil. En efecto, la reestructuración industrial espontánea plantea serios problemas de carácter político y social por sus implicaciones en términos de desempleo y deterioro regional.

La programación y progresividad de la reestructuración supone una interferencia en los mecanismos de mercado que se contrapone al énfasis librecambista característico del orden de postguerra. De allí el esfuerzo por mantener esta cuestión circunscrita a ciertas ramas y sectores específicos que son presentados como casos críticos, sin por ello renunciar a la lógica global de la liberalización. Este fenómeno está ligado al auge del llamado "neoproteccionismo" y a la protección selectiva. Esta política se ha seguido de manera fundamental en ciertos sectores particularmente afectados por la competencia al interior del bloque de los países capitalistas avanzados (industria del acero, automotriz, etc.), asf como también aquellos en los cuales el grueso de la oferta importada es provista por los 
llamados "NIC's" (textiles, calzado, productos electrónicos de consumo, etc.) .

La programación de la reestructuración implica, sin embargo, un conflicto potencial con los sectores más transnacionalizados del capital, por cuanto supone una reducción en su capacidad para moverse iibremente. No obstante, en la medida en que esta política se desarrolla por la vía del subsidio a la producción local, su carácter "disruptivo" se reduce sensiblemente por cuanto no interfiere, de manera directa, con la libre circulación de mercancías y el argumento del librecambio. Este último sigue siendo fundamental como instrumento ideológico no sólo para mantener relaciones relativamente fluidas entre los propios países capitalistas avanzados, sino además para mantener la iniciativa ideológica frente al IIamado "sur". EI "neoproteccionismo" o el proteccionismo selectivo aplicado a casos "críticos" permite mantener una retórica general de librecambio, a la vez que se implementa una protección puntual.

Para el caso de Estados Unidos, este dilema es particularmente claro. La economía norteamericana se encuentra en una fase de reestructuración en la cual dos características centrales son la "terciarización" de su economía y el desarrollo de una nueva "revolución tecnológica" basada en la microelectrónica y la informática. Esta reestructuración se produce en medio de una intensa crisis económica caracterizada por un marcado deterioro de todos los indicadores económicos y por una brusca contracción de ciertas ramas industriales. Estados Unidos conserva, en lo que respecta a las dos características del proceso de reestructuración más arriba señaladas un liderazgo relativamente importante en comparación al resto de sus competidores. De allí que sea altamente disfuncional a la estrategia de largo plazo de los sectores más dinámicos del capital norteamericano sacrificar un orden internacional abierto para reestructurar los segmentos "anticuados" de su aparato industrial.

\section{d) Transnacionalización y administración del orden internacional:} durante las dos décadas que siguieron a la terminación de la Segunda Guerra Mundiai, Estados Unidos contó con una hegemonía casi absoluta en el orden económico, político y militar, la que le otorgaba un liderazgo "natural" en el diseño primero y la administración después del orden internacional. Las instituciones creadas en Bretton Woods ocultaban, detrás de sus mecanismos impersonales, ventajas notorias para el polo hegemónico. Esta institucionalidad funcionó acertadamente por alrededor de dos décadas.

La evolución de ese orden mundial apuntaba, sin embargo, a la consolidación de procesos de desarrollo desigual y, en última instancia, al deterioro de la hegemonía norteamericana que lo había gestado. Esto último hacía inefectivos, y aún contraproducentes para el centro hegemónico, los mecanismos diseñados en la inmediata 
postguerra. Cuando los artificios de Bretton Woods se volcaron nítidamente en contra de Estados Unidos, fueron decretados extintos por la accción unila teral de Nixon en agosto de 1971. Esto plantearla, sin embargo, una nueva exigencia: la definición de un nuevo conjunto de normas de administración de la economía internacional en un contexto de competencia intercapitalista agudizada y de hegemonías no resueltas.

La experiencia histórica demuestra fehacientemente que los periodos con hegemonías no resueltas resultan en turbulencias $e$ inestabilidad. Tal ocurrió con el período que va de la Primera Guera Mundial al fin cle la Segunda Guerra, en el cual Gran Bretaña vio un debilitamiento en su posición de centro rector del capitalismo mundial, y lo propio está ocurriendo -salyando las distanciasen la coyuntura actual. En este contexto no debe sorprender el activo proceso de negociación intercapitalista que tuvo lugar en los setentas, como tampoco debe parecer extraño el presente intento de asignar al mercado el papel de ordenador e instancia disciplinaria del cuadro doméstico e internacional. En las actuales condiciones, asignar dicho papel de administración al mercado implica consolidar la posición de los relativamente las fuertes y debilitar la de Ios más expuestos. El gobierno norteamericano es consciente de estos efectos. No obstante, el riesgo y los costos de la regulación mercantil ya fueron demostrados por la experiencia de la década de los treinta. Una reiteración de sucesos en esa misma dirección sólo tendrfan una diferencia con aquella experiencia: su gravedad en las actuales circunstancias sería mucho mayor. Las expectativas puestas por muchos, en el sentido de que el proceso de transnacionalización y la constitución de un bloque de capital transnacional relativamente homogéneo resolvería los dilemas de administración del orden internacional, parecen haber perdido consistencia. La lógica mercantil, como expresión de la hegemonía de las fracciones más poderosas de capital, reproduce y amplifica el caos característico de la competencia oligopólica.

\section{LAS RESPUESTAS AL DESORDEN TRANSNAGIONAL Y ALGUNAS LEGGIONES DEL PROCESO DE TRANSNACIONALIZACIÓN EN LA POSTGUERRA.}

Las páginas anteriores nos permiten resumir algunas conclusiones. Una primera tiene que ver con el papel central que le cupo al proceso de transnacionalización en el periodo de postguerra tanto en Io que toca a sus efectos sobre el dinamismo económico como por lo que respecta a las características del orden económico que se gestó. Este papel crucial del proceso de transnacionalización tuvo, sin embargo, un carácter perverso. En efecto, desde la última parte de la década de los sesenta comienza a manifestarse una agudización en ciertas características contradictorias del patrón de crecimiento que se hallan profundamente vinculadas a la emergencia de la cri- 
sis económica en los setenta. Por un lado, se registra un incremento en los enfrentamientos intercapitalistas, como consecuencia de las dinámicas de desarrollo desigual desatadas en la inmediata postguerra. Por el otro, se hacen evidentes signos de tensión entre la dinámica de las fracciones transnacionalizadas del capital y los requerimientos de las economías domésticas -particularmente en aquellas que registran una mayor incidencia del fenómeno de crisis económica. Adicionalmente, el Estado aparece disminuido en su capacidad para afectar las condiciones económicas por la vía de manipular la demanda agregada como consecuencia de la creciente movilidad de un segmento importante de capital. Esta diversidad entre las necesidades de los aparatos productivos locales, la lógica transnacional de acumulación, la inefectividad de la política económica convencional y la necesidad de legitimación de un orden económico determinado resumen el nudo del conflicto económico de los setenta.

En Estados Unidos se han intentado tres respuestas a esta conjunción de crisis económica doméstica y desorden internacional en la última década, cada una de las cuales tiene importantes implicaciones para el proceso de transnacionalización. En lo que sigue haremos una breve caracterización de cada una de ellas, sin el ánimo de ir más allá que su identificación elemental.

La primera respuesta ensayada fue la del "Nixon shock", de agosto de 1971, que incluía elementos de fuerte nacionalismo económico y de asentamiento agresivo de la autoridad norteamericana. Estos dos elementos eran, precisamente, indicadores de la fragilidad de la posición de Estados Unidos en lo que respecta a la efectividad de los mecanismos de administración y control impuestos en Bretton Woods. La respuesta nacionalista de Nixon no constituye un cambio sustantivo en el objetivo político (el "internacionalismo" anterior a Nixon convergía con la promoción del interés nacional norteamericano), sino que representa un cambio radical en los métodos utilizados para hacer avanzar ese interés nacional.

Esta estrategia tenía un problema mayor, cual era el nivel de agudización del conflicto que provocaba al interior del bloque de los pafses capitalistas avanzados. Tal vẹz fue por ello que sólo tuvo sentido como una estrategia de corto plazo orientada a extraer concesiones. El rápido desplazamiento de Connally de la dirección del Departamento del Tesoro volvió a poner a su frente exponentes menos reacios a la negociación y al reconocimiento de la nueva realidad. Una reiteración de opciones de esta naturaleza sólo es concebible en el contexto de una severa profundización de la crisis económica, profundo deterioro en la legitimidad interna y marcada desarticulación del orden internacional. Obviamente, los contenidos profundamente recesivos de la polftica económica dominante, el fuerte endeudamiento interno e internacional $y$ la inestabilidad 
económica general hacen bastante riesgoso descartar de antemano la posibilidad de que se reitere una política de tal naturaleza. Las consecuencias son difíciles de imaginar. Esta política exigiría la constitución de un bloque social dispuesto a disciplinar al capital altamente móvil, programar una reestructuración industrial basada en las industrias hoy en crisis y sacrificar la apertura y la integración a la economía mundial en favor de una alternativa de autarquía y nacionalismo económico. Ciertamente esto implicaría desarticular políticamente al sector más dinámico del capitalismo contemporáneo interesado en mantener un orden internacional abierto del cual pueda extraer el mayor provecho posible haciendo uso de su capacidad para operar globalmente.

Una segunda respuesta también ensayada es la de fomentar la negociación y la cooperación en todos los ámbitos posibles, como un reconocimiento de la imposibilidad de imponer directrices unilaterales al orden mundial. El exponente más articulado de esta opción está representado en la Comisión Trilateral, una instancia de agrupamiento de personajes altamente representativos de los países capitalistas avanzados interesados en el mantenimiento de un orden internacional abierto. Sobre la Gomisión Trilateral se han escrito multitud de páginas, frecuentemente utilizando una aproximación conspirativa altamente inapropiada. En nuestra opinión, la Comisión se ha manifestado como una instancia de aproximación, discusión y reconocimiento explícito de la necesidad de negociar y coordinar posiciones comunes entre los principales socios del actual orden internacional. Esta posición vale tanto para lo que toca a las relaciones interestatales (reuniones cumbre) como para lo que se refiere a las relaciones entre cada Estado nacional, el capital transnacional y las necesidades de legitimación doméstica (recomendaciones de administración de la reestructuración y de negociación y compatibilización de los principios de la política industrial). Las propuestas de la Gomisión Trilateral parten de asumir un cierto nivel de contradicción en el corto plazo y sugieren mecanismos y alternativas para negociar y coordinar sus aristas más irritantes.

La "estrategia trilateral" se aplicó de manera más intensa durante los primeros años de la Administración Carter, concluyendo con resultados relativamente pobres. Al margen de su efectividad estratégica, la opción trilateral permanece abierta como una alternativa a la agudización del conflicto. En una fase de reestructuraciớn y transición como la presente, es probable que se requieran menos proyectos de largo plazo que estrategias de transición. En tal sentido, una propuesta que intenta reconocer y canalizar las contradicciones intercapitalistas puede tener, para ciertos segmentos del capital, un valor en sí mismo como un elemento que se opone a la desintegración del orden mundial contemporáneo.

Un tercer intento está actualmente en marcha. En él se reivin- 
Roberto Bouzas / Estados Unidos y el proceso de transnacionalización..

dica el liderazgo político y militar de Estados Unidos, a la vez que se intenta legitimar el mayor poderío relativo norteamericano por la vía de asignar al mercado un papel importante en el reordenamiento del escenario doméstico e internacional. Este intento de reasentamiento de la "autoridad" norteamericana genera una reacción más tenue que la opción nacionalista "tipo Nixon", por cuanto opera por la vía de reforzar las características centrales del orden económico de postguerra. Esta revitalización del rol del mercado implica asignar a la anarquía de la competencia oligopólica el papel de ordenador fundamental. Esta opción conlleva serios riesgos en lo que respecta a sus consecuencias sobre la coyuntura económica tanto como en lo que toca a la estabilidad del orden internacional, tal como ha quedado demostrado por la experiencia del último par de años.

Las tres opciones que hemos esbozado se han ensayado con escasos resultados en términos de diseñar un nuevo patrón de vinculación internacional. Una explicación para ello bien puede ser que en la actual coyuntura de reestructuración y transición la politica es tan solo un elemento que coadyuva pero no determina la dirección de los acontecimientos. Descubrir las tendencias centrales de esta reorganización excede las pretensiones de estas notas. En la medida en que el manejo de la coyuntura afecte de alguna manera la estabilidad de las tendencias de largo plazo, la discusión relativa al contenido de la política y a la caracterización de las respuestas estatales especificas no dejará de tener relevancia. 